\title{
Plataformização, tecnopopulismo e desintermediação das fontes em ataques ao jornalismo no Instagram
}

Platformization, techno populism and disintermediation of sources in attacks on journalism on Instagram

Plataformización, tecnopopulismo y desintermediación de las fuentes en los ataques al periodismo en Instagram

\author{
Lia Gabriela PAGOTO \\ Universidade Federal de Santa Catarina (UFSC) - Brasil \\ liagabrielapagoto@gmail.com
}

\section{Raquel Ritter LONGHI}

Universidade Federal de Santa Catarina (UFSC) - Brasil

raqlonghi@gmail.com 


\title{
Resumo
}

Este artigo discute como o processo de plataformização pode contribuir para dilatar a crise de deslegitimação do Jornalismo. Associando a lógica de funcionamento das plataformas de redes sociais a uma retórica de descredibilização da imprensa, políticos como Jair Bolsonaro passam a utilizar as redes sociais para enunciar sua "verdade" diretamente ao seu público. Observamos o impacto dessa práxis através da análise de comentários em notícias de dois veículos brasileiros no Instagram: CNN Brasil e Folha de S. Paulo, numa amostra que compreende 33.651 posts. O resultado assinala uma correlação discursiva entre a gramática dos usuários e a de Bolsonaro e um aumento de ataques à imprensa em notícias relacionadas ao Presidente, revelando assim, o poder das plataformas.

Palavras-chave: Instagram, desintermediação das fontes, jornalismo, tecnopopulismo, análise de conteúdo.

\begin{abstract}
This article discusses how the platformization process can contribute to dilate the delegitimization crisis of Journalism. By associating the logic of operation of social media platforms with a rhetoric of discrediting the press, politicians like Jair Bolsonaro start to use social media to spread their "truth" directly to their audience. We observed the impact of this practice through the analysis of comments in news from two Brazilian vehicles on Instagram: CNN Brasil and Folha de S. Paulo. The sample includes 33,651 interventions.The result marks a discursive correlation between the grammar of users and Bolsonaro and shows an increase of attacks on press news related to the President, revealing the power of techno populism on platforms.
\end{abstract}

Keywords: Instagram, disintermediation of sources, journalism, techno populismo, content analysis.

\section{Resumen}

Este artículo explora cómo el proceso de plataformización puede contribuir a amplificar la crisis de deslegitimación del periodismo. Al asociar la lógica de funcionamiento de las plataformas de medios sociales a una retórica de desacreditar la prensa, políticos como Jair Bolsonaro utilizan los medios sociales para enunciar su "verdad" directamente a sus audiencias. Observamos el impacto de esta práctica a través del análisis de los comentarios en dos medios brasileños en Instagram: CNN Brasil y Folha de S. Paulo, en una muestra de 33.651 intervenciones. El resultado presenta una correlación discursiva entre la gramática de los usuarios y la de Bolsonaro y un avance de los ataques a la prensa en las noticias relacionadas con el presidente, exponiendo el poder del tecnopopulismo en las plataformas.

Palabras clave: Instagram, desintermediación de fuentes, periodismo, tecnopopulismo, análisis de comentarios. 


\section{Introdução}

A discussão sobre o papel das plataformas no remodelamento dos comportamentos sociais e das instituições está em toda parte. Da política ao marketing, do jornalismo ao entretenimento, ocorre uma espécie de reorganização das formas de socialidade. Este artigo discute o impacto do modo de funcionamento das plataformas na crise do jornalismo em um cenário de polarização social que se instaurou em sistemas políticos ao redor do mundo, especialmente, no Brasil. Para Da Empoli (2019), o caos é o cenário perfeito para a proliferação do ódio e da frustração, principais fontes de alimento das ideias populistas contemporâneas. Nesse sentido, é preciso se debruçar sobre essa capacidade dialética das plataformas de, ao mesmo tempo, propiciar um lugar de fala a diversos sujeitos ao passo que organiza e define quem terá mais ressonância, pois essa lógica inaugura um campo de embates que tem incidido em reconfigurações e dificuldades para diversas instituições.

Para o jornalismo, uma das implicações decorrentes da expansão e da incorporação do uso das plataformas na vida cotidiana é a ameaça à sua credibilidade. $\mathrm{O}$ relacionamento entre plataformas e o jornalismo e o papel fundamental de grandes empresas de tecnologia como Google, Facebook, Twitter, dentre outras, nessa relação, como demonstrou a pesquisa multianual do Town Center for Digital Journalism, coordenada por Emily Bell, nos anos de 2017, 2019 e 2020, é ilustrativa. Além de passarem a ser protagonistas no papel de emissoras de notícias e principal porta de entrada para o conteúdo noticioso, as plataformas foram criando oportunidades editoriais, numa dinâmica de retroalimentação contínua. Isso teve vantagens e prejuízos. Um desses prejuízos, como observam Van Dijk et al. (2018), é que, valores-chave da instituição jornalística, como independência e fornecimento de informações confiáveis, estão sob crescente escrutínio público. No caso de fontes governamentais e políticas, a utilização das plataformas como veículo para contato direto com seu público, evitando a intermediação jornalística, trouxe ao cenário uma imagem de "verdade" que repousa, muitas vezes, no equívoco e na confusão e, até na má fé. Este tem sido o caso do governo brasileiro de Jair Bolsonaro que, desde os primeiros meses de sua administração, elegeu as redes de mídia social Twitter e o Facebook como suas fontes oficiais. No primeiro, o presidente, através do seu perfil, seguidas vezes anuncia novos ministros e demite outros; no segundo, Bolsonaro faz "lives" semanais. No caso, trata-se de dar seguimento a uma estratégia que o então candidato já vinha fazendo: usar as redes sociais como o principal palanque e forma de comunicação. Para o professor Camilo Aggio, “a descentralização da comunicação —ou desintermediação, como chamam alguns- está no cerne da ascensão de radicalismos de extrema-direita ao redor do mundo" (Aggio, 2020). Este processo de deslegitimação, também afiançado por figuras políticas e pelo uso das plataformas, acirra conflitos entre leitores, 
e entre leitores e veículos de imprensa, em ações marcadas pela desinformação, informação enganosa e fake news (Giusti \& Piras, 2021).

Na pandemia do Coronavírus a desinformação tornou-se onipresente em todos os perfis da Presidência e de alguns órgãos públicos, como o Ministério da Saúde e o das Comunicações, entre os anos de 2020 e 2021. Em meio a essa miríade de desinformação, as plataformas que hospedam tais perfis foram chamadas a tomar medidas de controle desses conteúdos mas, no caso do Brasil, somente no mês de março de 2021 é que três delas tomaram a primeira medida no sentido de coibir tais práticas. $\mathrm{O}$ Twitter removeu dois posts do presidente Bolsonaro que mostravam vídeos em que ele caminhava com seguidores e falava contra medidas de prevenção ao Coronavírus, como o isolamento; no dia seguinte, Facebook e Instagram removeram posts similares (Newman et al., 2021, p. 116). Em abril de 2021, a agência de checagem Aos Fatos divulgou que identificou 2.805 informações falsas ou enganosas proferidas pelo Presidente do Brasil durante 833 dias exercendo o mandato. (Newman et al., 2021, p. 117).

A estratégia de desinformação anda lado a lado com iniciativas de descredibilização do jornalismo, como citado anteriormente. No Brasil, vários são os casos em que o presidente e seus apoiadores atacam veículos da imprensa, e profissionais. É exemplar, nesse sentido, a série de ataques sofridos pela jornalista Patrícia Campos Mello após a publicação de uma reportagem sobre o disparo de fake news financiado por grupos de empresários pró-Bolsonaro, duas semanas antes das eleições de 2018. O presidente, seus apoiadores e alguns políticos fizeram uma verdadeira cruzada digital de difamação da profissional, chegando a ameaças não somente à sua honra, mas também à sua família (Mello, 2020).

No seu relatório anual sobre violência contrajornalistas, a Federação Nacional dos Jornalistas identificou, em 2020, 428 casos de ataques a profissionais, $105,77 \%$ a mais do que no ano de 2019. Tal número está associado "à sistemática ação do presidente da República, Jair Bolsonaro, para descredibilizar a imprensa e à ação de seus apoiadores contra veículos de comunicação social e contra os jornalistas", aponta o documento. Uma situação que foi agravada em 2020, "quando a cobertura jornalística da pandemia provocada pelo novo coronavírus foi pretexto para dezenas de ataques do presidente e dos que o seguiram na negação da crise sanitária" (Fenaj, 2021, p. 6).

Levando em conta que os efeitos da desinformação permeiam o ecossistema comunicacional digital, especialmente no que diz respeito às plataformas de redes sociais e usuários, neste artigo analisamos de que modo se engendram os discursos que atacam ou descredibilizam veículos de imprensa ou jornalistas através de comentários no Instagram. De modo específico, observamos se alguma pauta jornalística reúne um maior número de comentários de ataque e questionamos se é possível traçar um padrão discursivo que aproxima a retórica de ataque à imprensa de figuras como o Presidente Jair Bolsonaro e os comentários analisados. Para verificar essa prática de forma empírica, 
observamos os comentários realizados em posts veiculados entre os dias $10 \mathrm{e}$ 29 de outubro de 2020, nas contas do Instagram de veículos de legado (legacy media), o jornal Folha de S. Paulo, e a CNN Brasil. A rede social Instagram foi escolhida tendo em vista seu crescimento com fonte de informação, atualmente $30 \%$ dos brasileiros utilizam a plataforma para essa finalidade, segundo o Digital News Report 2020 (Newman et al., 2021). Os veículos foram escolhidos por representarem segmentos distintos -impresso e televisão- e por possuírem uma forte presença na rede, ambos com mais de 2 milhões de seguidores.

A amostra analisada por este estudo compreende 33.651 comentários. Para captura, seleção e análise utilizamos uma metodologia que combina os métodos digitais - sobretudo para coleta, mapeamento e classificação da informaçãoe a análise de conteúdo, empregada para realizar a categorização dessas intervenções dos usuários.

\section{Tecnopopulismo, desinformação e um jornalismo em crise}

A transformação de uma sociedade em rede para uma sociedade plataformizada e de uma cultura participativa para uma cultura de conectividade (Van Dijck, 2013) teve impactos nas mediações em rede contemporâneas. Tais mediações, como mostra D'Andrea (2020), são, por padrão, realizadas em ambientes privados, opacos e plataformizados. Essa ambiência enfraquece "os limites entre o que é público e o que é privado, ou entre o que é de interesse comum e o que é, acima de tudo, um negócio muito lucrativo" (D'Andrea, 2020). Segundo Van Dijck, Poell e Waal (2018) a ascensão das plataformas digitais é ovacionada como uma força de progresso econômico e tecnológico, algo do qual todos podem se beneficiar. Mas a riqueza da conectividade proporcionada por essas superestruturas não causa transformações somente do ponto de vista econômico. O que o surgimento das plataformas impõe é uma reorganização fundamental das relações econômicas e sociais pré-existentes.

A participação do público nas notícias certamente não foi criada junto com a ascensão ao mundo virtual, mas as plataformas de redes sociais expandiram essa capacidade, inclusive conferindo uma ambivalente autonomia ao percurso informativo do leitor. Tais plataformas, de fato, configuram-se como laboratórios essenciais para a proliferação e sedimentação de desinformação e de fake news (Giusti \& Piras, 2021; Alcott \& Genzkow, 2017). A desinformação é descrita por Giusti e Piras (2021) como o produto da construção de um propósito falso, ao passo que informação enganosa diz respeito a uma peça de informação incompleta, vaga, enganosa ou ambígua. Tais práticas foram sedimentando, com os meios digitais, o fenômeno das fake news, que, segundo as autoras, podem ser entendidas como uma versão tecnológica avançada da informação enganosa, significando peças de informação manipuladas intencionalmente, que aparecem especialmente nas mídias sociais e na internet. (Giusti \& Piras, 2021, p. 3). Para Alcott e Gentzcow (2017), fake news são artigos de notícias 
intencional e verificavelmente falsos, que podem enganar os leitores. Ainda que não tenham origem nas plataformas, desinformação, informação enganosa e fake news (Fallis, 2015) são potencializadas nesses ambientes. A combinação de fake news, algoritmos e teorias da conspiração, segundo Da Empoli (2019) permite disseminar ódio, medo e influenciar eleições, como se verifica na ascensão de líderes populistas, como Jair Bolsonaro, que representam o chamado tecnopopulismo.

O projeto "Eleições sem Fake", coordenado pelo professor Fabrício Benevenuto, da Universidade Federal de Minas Gerais, monitorou as principais redes sociais e grupos públicos no WhatsApp (Mello, 2020) mapeando algumas das principais notícias falsas ou distorcidas que circularam em 2018. Conforme Mello, o projeto levantou que:

Mensagens, em sua maioria falsas, induziam a conclusões enganosas, descontextualizavam declarações ou mostravam acontecimentos de outros países como se tivessem ocorrido no Brasil. Também havia muitos memes ou deboche, que não chegavam a ser notícias falsas mas atuavam na construção e disseminação de narrativas equivocadas. (Mello, 2020, p. 34)

Um dado estarrecedor sobre o alcance das fake news dá conta de que as dez notícias falsas mais populares checadas pela Agência Lupa em agosto de 2018 tiveram, juntas, 865 mil compartilhamentos só no Facebook (Mello, 2020).

O uso evidente de plataformas de mídia por figuras políticas, como o Presidente do Brasil, Jair Bolsonaro, e pelo ex-Presidente dos Estados Unidos, Donald Trump, ao lado de constantes ataques direcionados às instituições jornalísticas, também contribuiu para a solidificação de uma crise de credibilidade no campo. Em nome de comunicar a (sua) verdade aos seguidores de suas redes sociais, essas figuras hostilizam e frequentemente desacreditam o jornalismo. Usuários e seguidores, desta forma, são incentivados sistematicamente a buscar informações em fontes alternativas, endossadas por eles, como é o caso da recomendação do filho do Presidente Bolsonaro, o senador Flávio Bolsonaro, que em um tuíte de maio de 2020 indicou: 
Figura 1. Tuíte de Flávio Bolsonaro

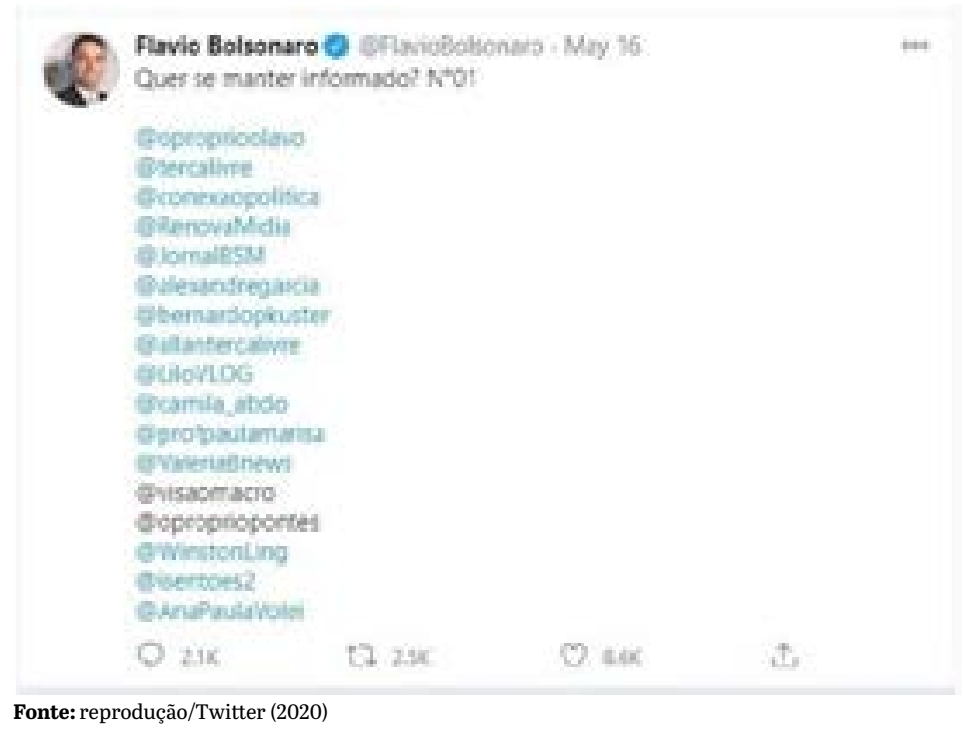

Como apontou Flores (2020, p. 3), inscritas na "era de desintermediação entre as fontes e o público", é comum, também, as fontes recuarem ou desmentirem informações anteriormente fornecidas à imprensa e até mesmo apagarem seus posts, especialmente frente a uma reação negativa da opinião pública. A negação da imprensa profissional é apontada por Cesarino (2019) como estratégia de líderes como Bolsonaro para validar a criação de um canal direto e exclusivo de comunicação com o seu público. A "devolução de acusações e a deslegitimação de instâncias de produção de conhecimento autorizado na esfera pública" (Cesarino, 2019, p. 533), características do que a autora chama de populismo digital, também podem ser reconhecidas na lógica do sistema bolsonarista (Figura 2), que acusa sistematicamente a imprensa de disseminar falsas informações, definidas como "fake news", numa subversão do termo. 
Figura 2. Tuítes do presidente Jair Bolsonaro
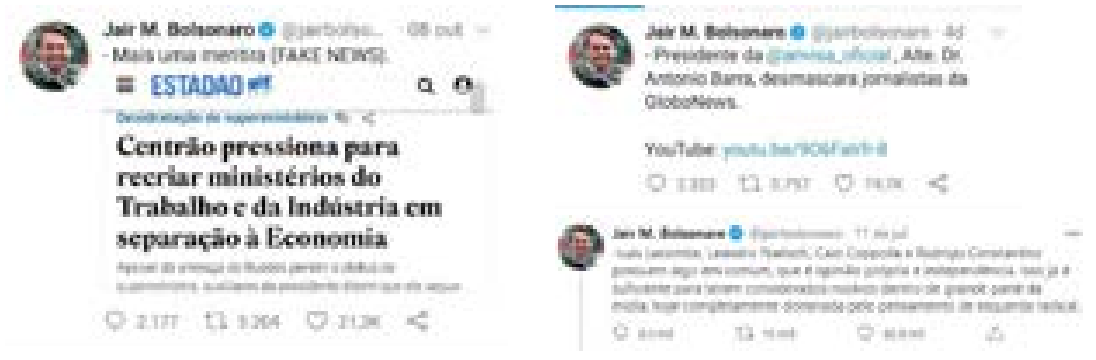

Fonte: reprodução/Twitter (2020)

As plataformas de redes sociais são importantes ambientes de relacionamento. Em um estudo de consumo e recepção de notícias jornalísticas que circularam na internet, Winques (2020), apontou que "os sujeitos usam um conjunto de heurísticas ou atalhos mentais para avaliar a credibilidade de uma fonte ou mensagem". A autora pensa sobre a exposição e o consumo seletivo de conteúdos em plataformas.

No que tange à formação de opiniões, que encontram nos algoritmos e no silêncio dos fatos uma verdade autoconstruída, as plataformas digitais e as crenças pessoais servem de confirmação às pressuposições dos grupos e estes, por sua vez, amplificam aquelas informações que se revelam adequadas aos seus modos de pensar. (Winques, 2020, p. 327)

Ao analisar o discurso de parlamentares populistas, Da Empoli (2019), apontou que as plataformas de redes sociais são armas poderosas para esses políticos. Para o autor, o sucesso desses novos agentes, os quais chamou de tecnopopulistas, se deve, além do fato de eles terem sabido captar, antes dos outros, os sinais da mudança em curso, à "forma pela qual se aproveitaram disso para avançar da margem para o centro do sistema [...] o populismo tradicional que se casa com o algoritmo dá à luz uma temível máquina política” (Da Empoli, 2019, p. 27). Segundo Mazzarella (2019), as plataformas produzem, paradoxalmente, o efeito de ausência de mediação entre líder e povo. O teórico político argentino Ernesto Laclau (2013) também lembra que uma das gramáticas do discurso populista é a dicotomia amigo/inimigo, a formação de um "nós" contrário a um “eles”. É uma lógica que se constrói através do antagonismo.

O já citado relatório Violência contra Jornalistas e Liberdade de Imprensa no Brasil referente ao primeiro semestre de 2020 da Federação Nacional dos Jornalistas (Fenaj) contabilizou ataques contra o Jornalismo por parte do presidente Bolsonaro. Publicado em julho de 2020, registrou 245 ocorrências no período, “[...] sendo 211 categorizadas como descredibilização da imprensa, 
32 ataques pessoais a jornalistas e dois ataques contra a Fenaj. São quase dez ataques ao trabalho jornalístico por semana" (Fenaj, 2020).

Para além dos números, os dados mostram que as notícias sobre as ações do governo ou a postura do presidente sobre diversos assuntos transformam a imprensa em sua "inimiga", com a construção de uma narrativa de ataques com o objetivo de promover a descredibilização do trabalho jornalístico e da credibilidade da produção de notícias. Algumas vezes o presidente coloca a imprensa e os jornalistas como "inimigos do País", por conta de coberturas que o desagradam. (Fenaj, 2020)

No mesmo compasso, os leitores têm se voltado para redes sociais como forma de consumir, discutir e replicar notícias, além de participar de outras formas de engajamento político (Nielsen et al., 2019). O Digital News Report 2020 (Newman, 2020) apontou um aumento considerável no consumo de notícias por redes sociais pelos brasileiros (cresceu de 47\% em 2013 para 83\%) e o Instagram apareceu como a rede social com maior crescimento no país nesse segmento. E é nessa arena, portanto, que vamos observar como se acirram as disputas pelas narrativas sobre os eventos e que incidem sobre a autoridade da imprensa.

\section{Metodologia}

O percurso metodológico considerou revisão bibliográfica sobre plataformização e o papel de figuras políticas nas dinâmicas de circulação de conteúdo nas redes sociais. A etapa empírica compreende a análise de um recorte de posts veiculados entre os dias 10 e 29 de outubro de 2020, nas contas do Instagram da Folha de S. Paulo, com 2,4 milhões de seguidores, e da CNN Brasil, 2,3 milhões. Nossas perguntas de pesquisa são: como se engendram os discursos de ataque à imprensa nos comentários realizados por usuários das plataformas de redes sociais? Que pauta jornalística reúne um maior número de comentários de ataque? É possível traçar um padrão discursivo que aproxima a retórica de ataque à imprensa de figuras como o Presidente Jair Bolsonaro e os comentários nos perfis jornalísticos analisados?

Para respondê-las, realizamos a raspagem dos posts através dos módulos Profile Scraper e Coments Post Scraper da plataforma PhantonBuster. A primeira fase resultou em 76 posts da CNN Brasil, com 44.537 mil comentários, e 286 posts da Folha de S. Paulo, com 96.686 mil comentários. O primeiro filtro utilizado para restringir o objeto de estudo em amostras analisáveis foi escolha de cinco editorias: Covid, Editorial, Política, Internacional, Cotidiano. Para cada seção, foram selecionados os três posts mais comentados nos respectivos veículos. A segunda fase de raspagem compreendeu a coleta dos comentários de cada um dos 27 posts (derivados de cinco editorias das Folha de S. Paulo, e quatro da CNN Brasil) selecionados para compor a amostra, o que resultou em 33.651 comentários, sendo 18.073 relativos à primeira e 15.578 à segunda publicação. 
Após a delimitação do grupo de dados que comporão a amostra, seguimos para a etapa de limpeza dos dados através da categorização. Para tanto, a partir dos parâmetros de repetição léxica observados, os comentários relativos a veículos e profissionais de imprensa foram agrupados em três categorias, que tiveram como finalidade a otimização da análise, conforme o Quadro 1.

Quadro 1. Categorias de comentários

(C) Catteanus of comarisins

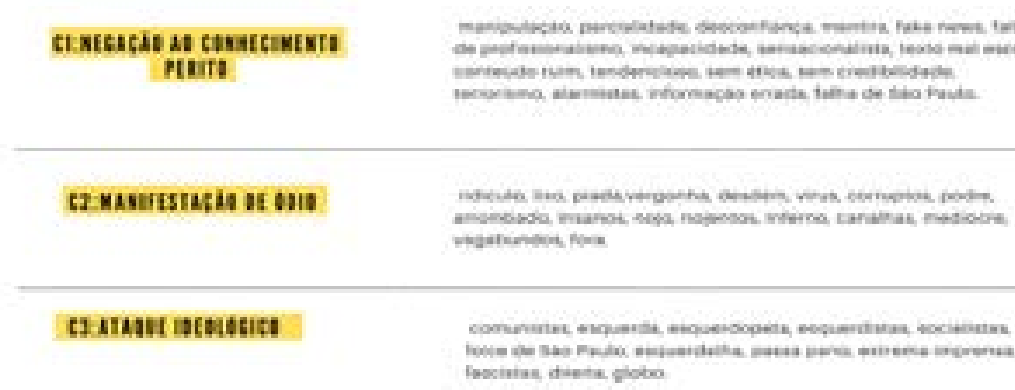

Fonte: Elaboração própria

\section{Análise exploratória}

No recorte temporal da amostra, a CNN Brasil postou 76 notícias. Foi possível perceber um maior direcionamento editorial para as pautas cotidianas, com $34 \%$ dos posts. Além dessas, que tratam de descobertas ou curiosidades da ciência, a conta no Instagram do veículo também se dedica à cobertura de eventos internacionais, figurando como a segunda editoria com o maior número de posts: 25\%. Desta forma, "Cotidiano" e "Internacional”, consequentemente, são as editorias que recebem o maior número de comentários de usuários, de maneira geral e não no recorte.

A figura 3 sistematiza os comentários categorizados nas postagens relacionadas às notícias publicadas pela CNN Brasil no Instagram. As diferentes cores sinalizam as editorias e os círculos mostram as categorias de análise. 
Figura 3. Comentários categorizados-CNN Brasil

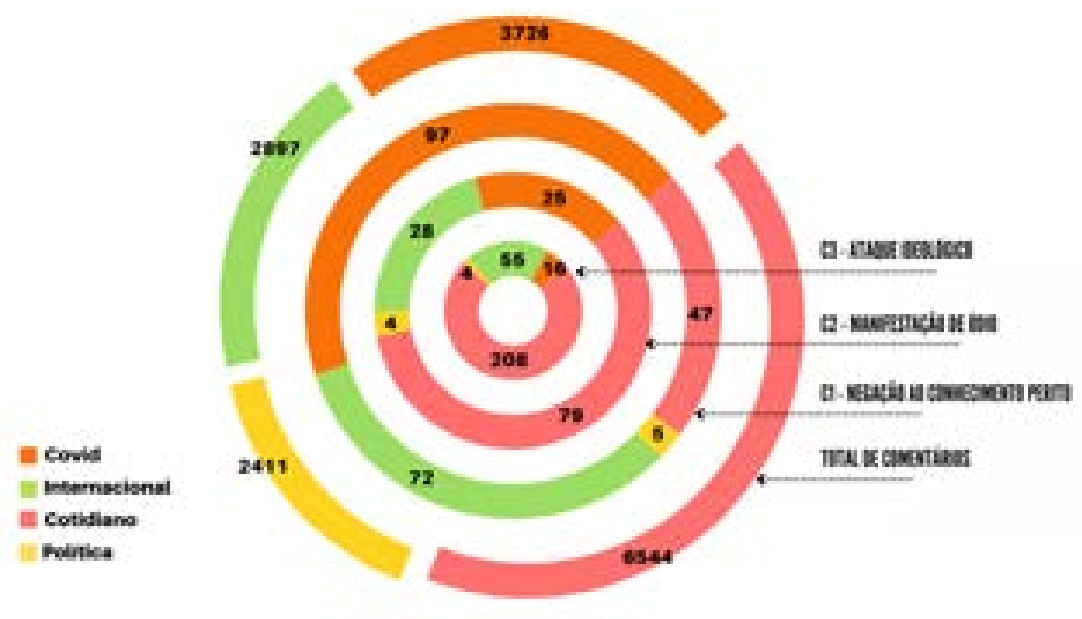

Fonte: Elaboração própria

Na amostra coletada, a editoria "Covid" foi a segunda com maior número de comentários, nos quais houve o maior número de categorizações em C1, representando 70\% da amostra (138). Dois dos posts desta editoria se dedicaram a divulgar informações sobre vacinas; a decisão presidencial de não comprar a vacina chinesa Coronavac foi o tema do post que recebeu o maior número de comentários.

A editoria "Política" recebeu apenas dois posts e houve uma distribuição quase equânime entre os comentários de C1, C2 e C3. Foi a que menos teve retorno de comentários categorizados, representando 0,5\% da amostra. $\mathrm{Na}$ principal seção abordada pelo veículo, a "Cotidiano", notamos a predominância de comentários categorizados em $\mathrm{C}_{3}$, colocando a emissora como um veículo alinhado à esquerda, ao comunismo e contra o governo brasileiro.

No perfil da CNN Brasil no Instagram a pauta "Internacional" também tem destaque. É nesta editoria que se concentra o maior percentual de comentários categorizados, 5,3\%. Também foi possível notar a predominância de comentários C1, 46\% de um universo de 155 das intervenções dos usuários.

No geral, 14,5\% dos comentários recebidos pela CNN Brasil durante o período analisado foram de negação ao conhecimento perito, de ódio ou de ataque ideológico. O Quadro 2 mostra um recorte de comentários retirados da amostra analisada do perfil da CNN Brasil. 
Quadro 2. Amostra de comentários CNN Brasil

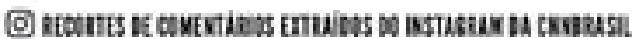

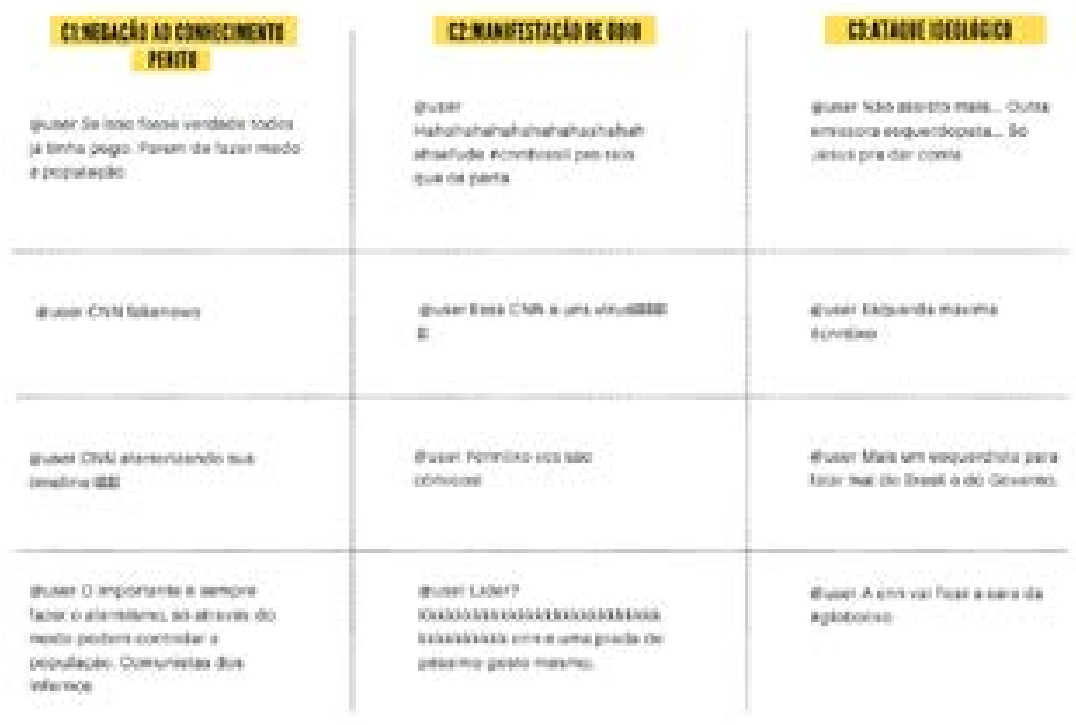

Fonte: Elaboração própria

Durante o período temporal analisado, foi verificada uma maior atuação do jornal Folha de S. Paulo, em seu perfil, com uma média de 14, posts diários. Desses, $18 \%$ estão relacionados à política nacional, sendo, consequentemente, os que recebem o maior número de comentários. No total das intervenções feitas por usuários em conteúdo veiculado pela Folha de S. Paulo, 38\% se concentram em temáticas relacionadas à política brasileira (Figura 4). 
Figura 4. Comentários categorizados-Folha de S. Paulo

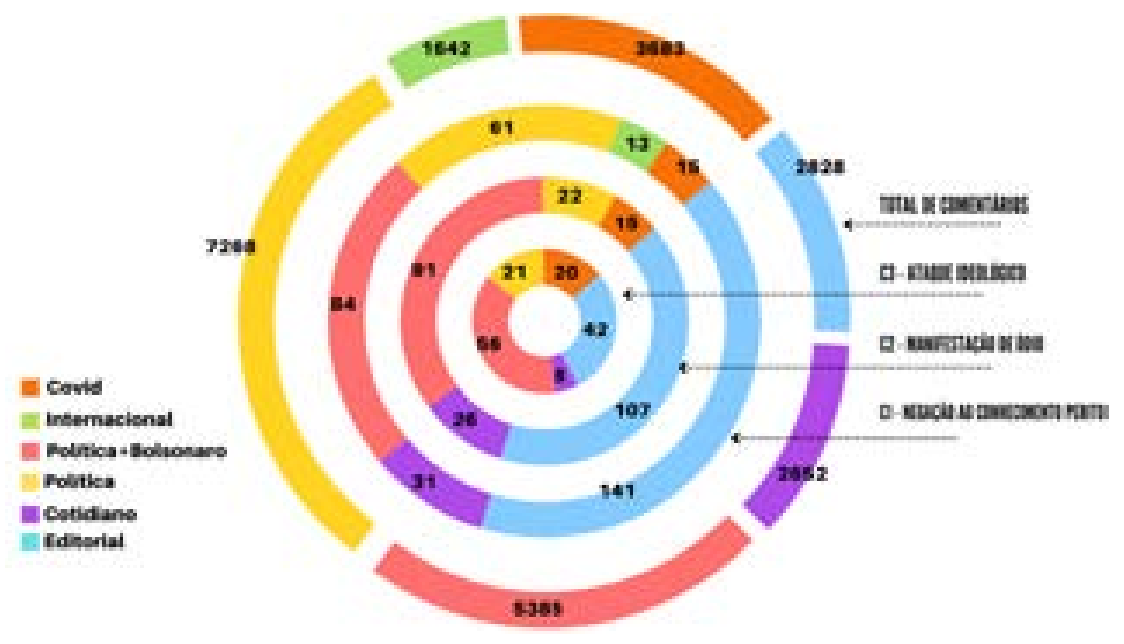

Fonte: Elaboração própria

A análise mostrou que a editoria "Política", diferentemente do observado na amostra da CNN Brasil, é a que mais recebe comentários. Nesta seção, a pesquisa apontou que, de todos os comentários realizados, 1,4\% se enquadram nas categorias $\mathrm{C} 1, \mathrm{C}_{2}$ ou $\mathrm{C} 3$, ou seja, distribuídos nas três categorias. Foi possível, ainda, verificar o seguinte parâmetro: sempre que uma notícia desta editoria faz menção a Jair Bolsonaro, o número de comentários relacionados às categorias C1, C2 e C3 aumenta significativamente. Assim, a editoria "Política" foi analisada, também, através de uma sub-editoria, denominada PolíticaBolsonaro. Essa abordagem replicou o modus operandi e selecionou os três posts mais comentados desta sub-editoria. A análise mostrou que quando acontece a conjunção da pauta Política+Bolsonaro, os comentários categorizados em C1, C2 e C3 chegam a 4,28\% do todo. Nessa dimensão específica também há a predominância de comentários de ódio e que fazem negação ao conhecimento perito, $75 \%$ do total (231 de 5.385 comentários).

O mesmo também foi observado durante a análise da seção "Editorial”, na qual os três posts mencionavam Bolsonaro. Nesses posts, o total de comentários analisados foi de 2.828. Desses, 10,25\% eram de uma das categorias C1, C2 ou C3. Os posts dessa editoria são marcados, na conta do veículo com o título "O que a Folha pensa”. Nesses posts, vimos a preponderância de ataques ideológicos ( $\left.\mathrm{C}_{3}\right)$, atribuindo ao veículo uma posição à esquerda do espectro político. Juntos, C3 (ideológico) e C2 (ódio) somam 85,5\% dos comentários categorizados (290). Uma hipótese que pode explicar este comportamento é o fato desta editoria demarcar o posicionamento do veículo de comunicação. 
Esta é uma análise inicial, mas pelo recorte é possível apontar que quando acontece a menção ao nome do Presidente, há incidência maior de comentários que parecem se inserir na retórica presidencial de descredibilização dos veículos de comunicação. No Quadro 3 é possível ver alguns recortes de comentários nos quais se identifica tal proximidade.

Quadro 3. Amostra de comentários Folha de S. Paulo

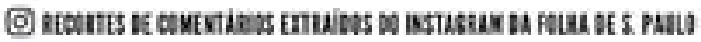

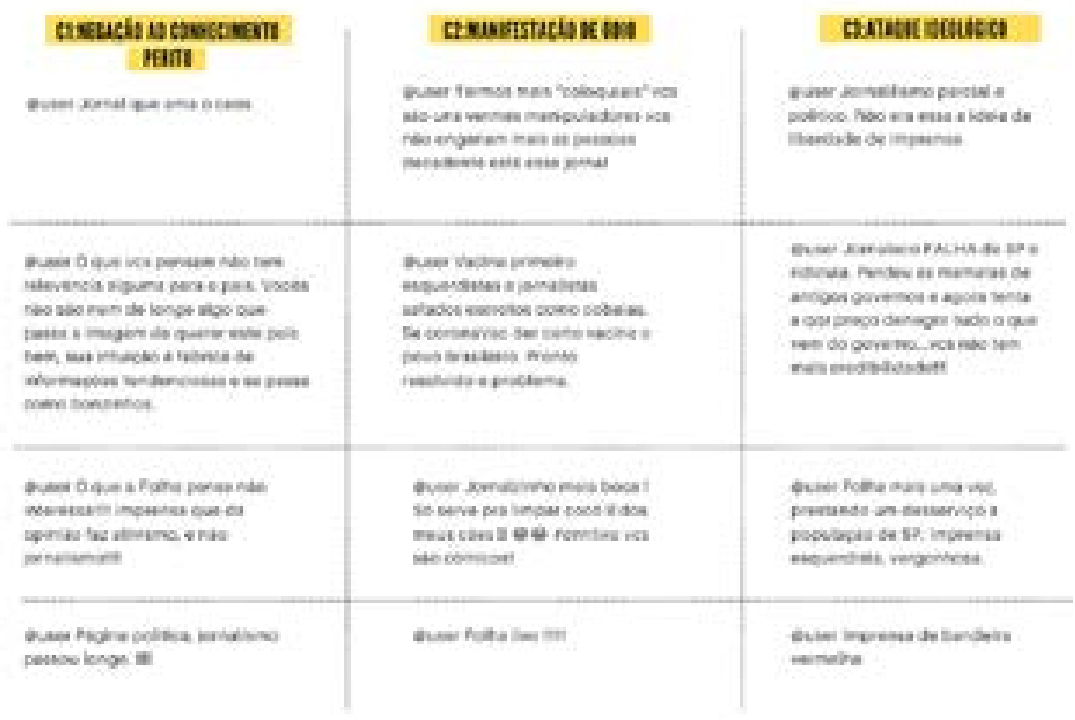

Fonte: Elaboração própria

Nas demais editorias avaliadas na amostra da Folha de S. Paulo, "Cotidiano", "Internacional" e "Covid", foi identificada uma certa estabilidade em relação às intervenções inseridas em $\mathrm{C}_{1}, \mathrm{C}_{2}$ e $\mathrm{C}_{3}$, ainda que seja possível notar uma incidência maior de comentários de negação ao conhecimento perito, como é demonstrado na Figura 4. Em relação a tais seções, foi possível anotar que quando a pauta se refere a temas sociais como violência de gênero, homofobia, religião e outros, há uma ocorrência maior de comentários de ódio. No total de comentários que compunham a amostra, $35 \%$ se enquadram em alguma das categorias. 


\section{Discussão}

Quadro 4. Perguntas de pesquisa e achados da investigação

\section{(O) PERGUKTAS E ACHADOS}

\begin{tabular}{|c|c|c|}
\hline 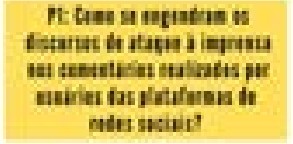 & 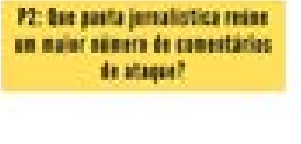 & 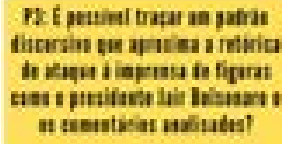 \\
\hline 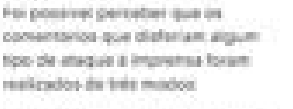 & 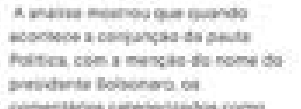 & 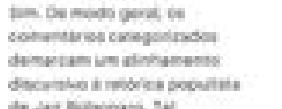 \\
\hline 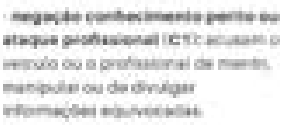 & 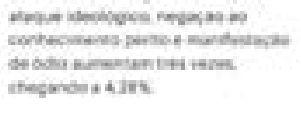 & 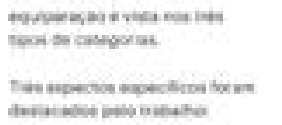 \\
\hline 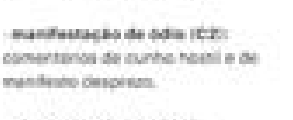 & 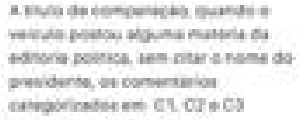 & 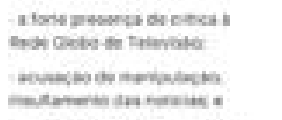 \\
\hline 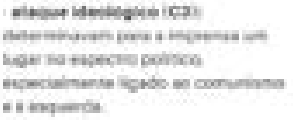 & 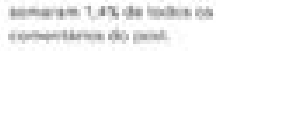 & 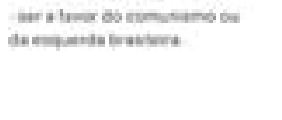 \\
\hline
\end{tabular}

Fonte: Elaboração própria

A partir da análise do corpus selecionado, pudemos ver um importante comportamento de ataque à imprensa, uma vez que $35 \%$ dos comentários foram categorizados segundo os critérios desta pesquisa. Ainda pudemos verificar que a pauta política, de forma ampla, incide em um aumento de comentários nocivos à instituição jornalismo. Já quando há a combinação "Bolsonaro" e "política", observamos um impacto relevante. Esse efeito foi identificável na parcela do corpus correspondente aos posts da Folha de S. de Paulo: quando a pauta é política mas não menciona de forma deliberada o nome do Presidente, os ataques são identificáveis, porém em menor número $(1,4 \%)$; ao realizar a combinação da pauta política com a menção ao nome de Jair Bolsonaro, os ataques classificados como negação ao conhecimento perito/ataque ao profissional, ideológico ou de ódio ganharam envergadura, aumentando três vezes mais, (4,28\%).

Ainda que na amostra de comentários da CNN Brasil não tenha sido possível notar o mesmo comportamento em relação à seção "Política", cabe ressaltar alguns apontamentos. Em relação à editoria "Covid", o recorte temporal desta pesquisa marcou o período de embate entre o Governador de São Paulo João Dória Jr. e o Presidente Jair Bolsonaro quanto à aquisição da vacina Coronavac. O presidente questionava a eficácia da vacina devido a sua origem. 
Os comentários de negação ao conhecimento perito apareceram de modo mais robusto na editoria Covid do que nas outras. Intervenções que apontaram um papel sensacionalista e alarmista que da mídia frente à pandemia foram as mais observadas na amostra. É possível observar como as falas do presidente deslegitimando e manipulando discursivamente um saber estabilizado no âmbito da ciência sobre a vacina também resultaram no questionamento do conhecimento que é produzido pela imprensa profissional.

Com relação aos ataques ideológicos, na análise dos comentários dos posts da CNN Brasil, também se notou, de modo mais amplo e simbólico, um fenômeno particular que pode ser entendido como uma hostilidade ostensiva à instituição jornalística. Apesar de se tratar de uma amostra, pareceu evidente que a Rede Globo de Televisão, mesmo não integrando a amostra deste artigo, é um dos veículos preferidos quando se trata de ataques à imprensa brasileira. Durante a análise, diagnosticamos 209 menções à empresa. As citações transitaram nas três categorias elencadas pelo trabalho.

As principais associações são com a hashtag \#globolixo, que circula há algum tempo e que é derivada de um movimento crítico à emissora cuja retórica é partilhada pelo Presidente e seus filhos (Figura 5). Em outubro de 2019, por exemplo, a hashtag teve mais de 300 mil menções e entrou nos trending topics do Twitter.

Figura 5. Túte do Deputado Eduardo Bolsonaro

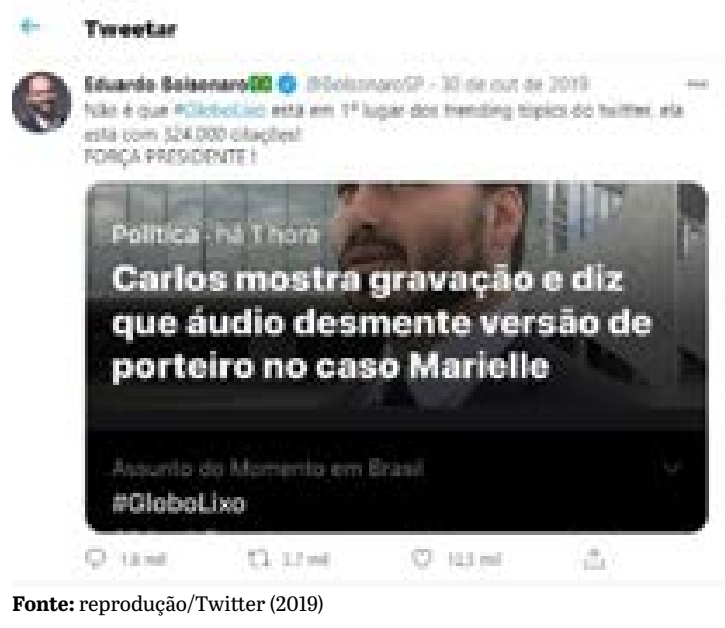

Considerando o contexto de uso da hashtag pelo Presidente, sua família e seus apoiadores, muitas intervenções que associam a Rede Globo de Televisão e a CNN Brasil foram categorizados como de cunho ideológico. Durante a análise da editoria "Cotidiano" comentários com menção à Rede Globo foram majorados, representando $58 \%$ da amostra observada. A frequência desse 
tipo de manifestação no Instagram da emissora parece fazer mais sentido, em detrimento da Folha de S. Paulo, pelo fato de serem duas redes de televisão. Algumas menções podem ser observadas na nuvem de palavras (Figura 6), gerada a partir dos comentários categorizados.

Figura 6. Nuvem de palavras a partir de comentários da amostra da CNN Brasil

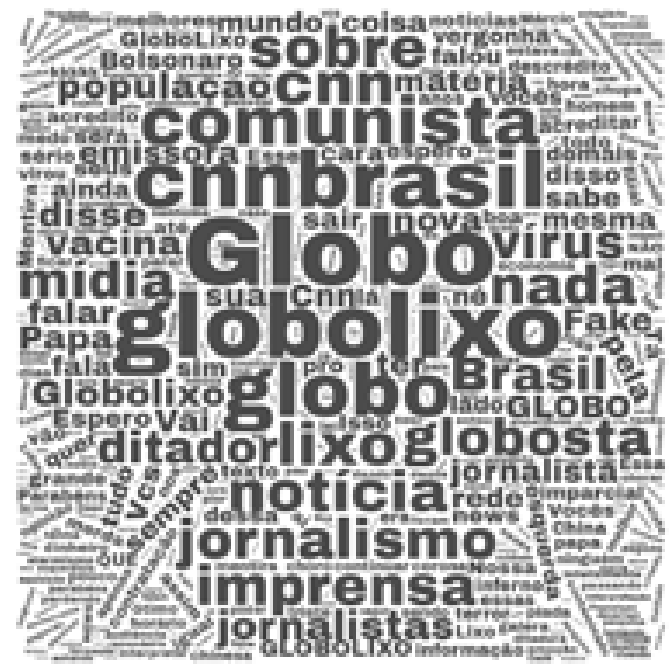

Fonte: Elaboração própria

De modo geral, os comentários categorizados demarcam um alinhamento discursivo à retórica bolsonarista. Tal equiparação é vista nos três tipos de categorias; elas mobilizam uma gramática comum à utilizada pelo Presidente que, além de atribuir à imprensa uma posição política avessa a sua —uma imprensa "vermelha", "esquerdopata" e "comunista"-, nega a posição de saber ocupada por ela, enunciando energicamente a existência de mentiras e manipulação de informações.

Em uma fala recente sobre a imprensa brasileira, pronunciada a apoiadores presentes na entrada do Palácio Alvorada, em 5 de janeiro de 2021, o Presidente afirmou: "[...] Teve esse vírus, potencializado pela mídia que nós temos aí. Essa mídia sem caráter que nós temos. [...]" (Foco do Brasil, 2021). ${ }^{1}$ Nesse mesmo canal, no dia 6 de janeiro, voltou a atacar: "[...] final de 2019 eu acabei com todas as assinaturas de jornais, Isto É, Veja, Estadão, O Globo, Folha, [...] Acabei. Quem

1 O canal Foco do Brasil, no Youtube, conta com 2.37 milhões de inscritos. Na aba "Sobre", na plataforma, o canal se apresenta da seguinte maneira: Olá! Seja bem-vindo ao perfil oficial do Foco do Brasil aqui no YouTube. O Foco do Brasil é uma mídia jornalística independente composta por Jornalistas, Cinegrafistas e Editores. O Foco publica diariamente as notícias e ações do Presidente Jair Bolsonaro, do Governo Federal e do nosso Brasil. Também produzimos nosso Jornal diário, sempre procurando prezar com o compromisso com a verdade. 
quiser comprar esse lixo, vai na rodoviária. Mas nem lixo, lixo é reciclável, isso não serve pra nada. Só fofoca e mentira o tempo todo".

Uma avaliação mais lúcida requer um mergulho nas profundezas da estratégia da comunicação do Presidente, porém, a partir das associações feitas nesse recorte é mister afirmar o poder de agenciamento discursivo exercido nesse contexto por Jair Bolsonaro, como num "eixo da equivalência, que traça uma contiguidade entre líder e povo”, já apontado por (Cesarino, 2019).

\section{Considerações finais}

A nova engenharia social resultante do modelo de relações que é propiciado nas plataformas veio acompanhada da desintermediação das fontes, deslocando os veículos de legado de seu papel de mediadores da informação. As fontes ferozmente assumiram a dimensão autônoma para informar seus públicos, fazendo com que jornalistas fossem demovidos de sua posição privilegiada de acesso exclusivo.

Apesar de serem estruturas privadas, as plataformas tornaram-se espaços substanciais para o debate público e têm sido estivas para a formação da opinião política em grande parte dos países na contemporaneidade. Essas estruturas também significam um processo proeminente de disseminação de desinformação. Neste recorte, buscamos observar como o fenômeno da desintermediação das fontes, propiciado pelo uso das plataformas de redes sociais por figuras políticas como o presidente do Brasil, Jair Bolsonaro, associado aos constantes ataques à imprensa brasileira, pode contribuir para dilatar uma das dimensões da crise pela qual passa o Jornalismo, especificamente no âmbito da sua deslegitimação e desacreditação.

A partir da observação e categorização de comentários em posts do Instagram da Folha de S. Paulo e da CNN Brasil, esta pesquisa buscou identificar parâmetros discursivos dos usuários. Identificados os fatores de repetição, as intervenções foram agrupadas em três grupos, C1, C2 e C3, quais sejam: negação ao conhecimento perito/ataque ao profissional, ideológico ou de ódio. Os três tipos de comentários se inscrevem no escopo da deslegitimação da instituição jornalística.

Como destacado na discussão dos resultados, há uma forte evidência de que o discurso de Bolsonaro em relação à imprensa se reflete de maneira significativa nos comentários analisados. Foi possível identificar uma interrelação discursiva entre a retórica bolsonarista e os comentários dos usuários, assinalando de maneira proeminente a disputa por esse lugar de poder dizer sobre "a verdade”. Também foi identificado na análise que quando o nome de Bolsonaro é mencionado na publicação, há um crescimento significativo do número de comentários de ataque à imprensa, demonstrando o impacto do tecnopopulismo nas plataformas. 
Como desdobramentos, em estudos posteriores, poderá verificar-se as conexões dos usuários, a fim de compreender como e se eles estão relacionados com a rede de Jair Bolsonaro, por exemplo, ou seus filhos, através de uma aproximação com a metodologia de análise de redes sociais. Uma outra possibilidade de estudo diz respeito ao agendamento das pautas através dos perfis de políticos, considerando a atuação em rede desses agentes.

\section{Referências bibliográficas}

Aggio, C. (2020). A eficácia da Hidroxicloroquina. Compolítica-Especial Coronavírus \#2. Recuperado de http://compolitica.org/novo/especial-coronavirus-2/

Alcott, H., \& Gentzkow, M. (2017) Social Media and Fake News in the 2016 Election. Journal of Economic Perspectives, Vol. 31, N. 2, p. 211-236.

Bell, Emily J., Owen, Taylor, Brown, Peter D., Hauka, Codi, \& Rashidian, Nushin (2017). The Platform Press: How Silicon Valley Reengineered Journalism.

Cesarino, L. (2019). Identidade e representação no bolsonarismo: corpo digital do rei, bivalência conservadorismo-neoliberalismo e pessoa fractal. Rev. antropol., São Paulo, v. 62 n. 3. Recuperado de https://www.revistas.usp.br/ra/article/view/165232/158421

Charaudeau, P. (2010). Discurso das mídias. São Paulo: Contexto.

Da Empoli, G. (2019). Os engenheiros do caos. São Paulo: Vestígio.

Dijk, J. (2013). The culture of connectivity: a critical history of social media. New York: Oxford University Press.

Dijck, J., Poell, T., \& Waal, M. de (2018). The platform society. New York: Oxford University Press.

Fallis, D. (2015). What is Disinformation? In Library Trends, Vol. 63, N. 3, 2015 ("Exploring Philosophies of Information", edited by Ken Herold), p. 401-426. The Board of Trustees, University of Illinois.

Fenaj. (2020). Presidente é o maior responsável por ataques à liberdade de imprensa no país. Fenaj. Recuperado de https://fenaj.org.br/presidente-e-o-maior-responsavel-por-ataques-a-liberdade-de-imprensa-no-pais/

Fenaj. (2021). Violência Contra Jornalistas e Liberdade de Imprensa no Brasil. Relatório 2020. Recuperado de: https://fenaj.org.br/wp-content/uploads/2021/o1/relatorio_fenaj_202O. pdf

Flores, A. M. M. (2020). Ataques à imprensa no canal de Jair Bolsonaro no YouTube, um estudo no contexto da pandemia de COVID-19. $18^{\circ}$ Encontro Nacional de Pesquisadores em Jornalismo. Recuperado de http://sbpjor.org.br/congresso/index.php/sbpjor/sbpjor2020/paper/viewFile/2761/1562

Foco do Brasil (2021). Presidente Jair Bolsonaro diz que o Brasil está 'quebrado'. Recuperado de https://www.youtube.com/watch?v=umqRyOYtaLk\&t=198s

Foco do Brasil (2021). Presidente Jair Bolsonaro comenta declaração 'Brasil Quebrado', Compra da Vacina, expõe Fake News. Youtube. Recuperado de https://www.youtube. com/watch?v=umqRyOYtaLk\&t=198s

Giusti, S., \& Piras, E. (Eds.) (2021). Democracy and Fake news. Information, manipulation and post-truth politics. London: Routledge.

Hofstetter, C et. al. (1999). Information, misinformation, and political talk radio. Political Research Quarterly, 52 (2), p. 353-369. 
Jasyn, L. Waggle, \& J. Fischer, D. R. (2015). An empirical examination of echo chambers in US climate policy networks. Nature Climate Change-Advance Online Publication. Recuperado de https://www.nature.com/articles/nclimate2666

Laclau, E. (2013). A razão populsita. São Paulo: Três Estrelas.

Mazzarella, W. (2019). The anthropology of populism: beyond the liberal settlement? Annual Review of Anthropology, v. 48, p. 45-6o. Recuperado de https://www.annualreviews.org/ doi/abs/10.1146/annurev-anthro-102218-011412

Mello, P. C. (2020). A máquina do ódio. Notas de uma repórter sobre fake news e violência digital. Companhia das Letras.

Nielsen, R. K. et al. (2019). Digital News Report 2019. Reuters Institute. Recuperado de http:// www.digitalnewsreport.org/survey/2019

Newman, N. et al. (2020). Digital News Report 2020. Reuters Institute. Recuperado de http:// www.digitalnewsreport.org/survey/2019

Pariser, E. (2011). O filtro invisível: o que a internet está escondendo de você. Rio de Janeiro: Zahar.

Rashidian, N. et al. (2020). Platforms and Publishers: The End of an Era. Tow Center for Journalism. Recuperado de https://academiccommons.columbia.edu/doi/10.7916/d8-sc1s-2j58

Rashidian, N. et al. (2019). Friend and Foe: The Platform Press at the Heart of Journalism. Recuperado de https://academiccommons.columbia.edu/doi/10.7916/d8-15pq-x415

Winques, K. (2020). Mediações algorítmicas e espiral do silêncio: as dimensões estruturantes igreja e sindicato na recepção de conteúdos noticiosos em plataformas digitais (Tese de Doutorado). Recuperado de https://repositorio.ufsc.br/handle/123456789/216018 